\title{
How Game Theory Impact International Relations
}

\author{
Hongji Zhang* \\ Beijing Normal University-Hong Kong Baptist University United International College (UIC), Zhuhai, 519087, China \\ "Corresponding author. Email: hzhjcn6745@outlook.com
}

\begin{abstract}
RAND Corporation, a famous American think-tank strategy research institution, started the research on how to better apply game theory on the analysis of foreign policy as early as in the 1970s, which shows that the United States attaches great importance to the research on the application of game theory to the field of international relations and diplomacy [1].
\end{abstract}

Keywords: Game theory, International relations.

\section{INTRODUCTION}

Obviously, when it comes to the current state of domestic research in China, this kind of theoretical topic is extremely helpful for the study of international relations and foreign policy-making. Our study is left far behind by those developed countries, so it is meaningful to explore the influence of game theory, especially in the study of international relations in China.

\section{THE GAME THEORY OF THE ROLE OF THE CONTROVERSY}

\subsection{The Controversy Surrounding the Game Theory}

In the 1950s, after international relations theory was undergoing the behaviorist revolution, the whole process not only introduced game theory into the study and application of international relations theory, but also caused a fierce debate on the applicability of the game theory in the field of international relations [2].

The behaviorist school of thought has started the debate, describes itself as a "scientific" theory, rejecting realistic and idealistic historical and philosophical normative research methods. What they do is advocating empirical or experimental research methods - holistic research, including category analysis and pattern analysis. Strategic research includes game analysis and decision analysis, and econometric research, statistical analysis, mathematical analysis, and computer analysis. They advocate the exclusion of value criteria from the research process, arguing that non-value or value-neutral research is possible; and advocate the refinement and quantification of theory and a more confirmation orientation. They sharply criticize realism in two main aspects: (1) Realism overemphasizes the role of power, and wrongly treats it as the core of the field of international relations, but ignores many other important factors such as ethics, morality, and law. (2) Realism lacks precision in defining concepts such as power, national interest, and parity. Based on the criticism of realism, they actively applied new scientific methods to study international relations, proposed empirical theories, and behavioral models, and sought to make the study of international relations clearer, more precise, and more scientific. On the one hand, the traditional school of thought believes that traditional research methods are still useful and essential, that philosophy, history, and the law should still be the basis of international relations research. And realist research methods are meticulous, precise, and logical. On the other hand, they criticize scientific behaviorism for overemphasizing empirical evidence at the expense of ignoring philosophical, historical, and ethical factors. They argue that the thrust of political science is different from the thrust of physics; scientific knowledge can be used to study historical facts, while understanding, wisdom, and instinct are only applied to the study of human relations; they advocate the scientific method often mistakenly treat the method as reality; the scientific method requires a high degree of measurability and precision, making it difficult to deal with the most volatile situations amid international politics [3]. 


\subsection{Ontological Debate}

In the field of international relations, many scholars working on international cooperation, arms control, or conflict studies prefer to publicize their idea on"prisoner's dilemma" and "who is the coward". However, many scholars believe that the game theory model is too simple and rigid in the complex international environment, and they constantly question its adaptability, i.e., the forms of activity of the international system cannot be understood simply by using the framework of game theory analysis. These scholars believe that the connotations of science are consistent, both in natural and social sciences, due to they adhere to positivism, which is an important result of the accumulation of knowledge in the Western intellectual community; objective facts and values can be separated, and that objective facts are independent of any theory; there are objective laws in sociology as in natural sciences, and that these laws can be discovered iii. Accordingly, positivism holds that putting the theory in the application is the only way to test a theory is true or not. However, I personally believe that some positivist assumptions are not fully justified. It is sometimes impossible to distinguish objective facts from subjective values in the study of social sciences, and it is often impossible to separate the subject of research from the object of research, or even to determine the objective facts themselves, so these basic assumptions of positivism cannot be applied to the social sciences, especially in the field of diplomacy. Just as Reflectivism values and emphasizes the interpretive nature of theories, the interconstitution of agents and structures, if you view game theory in their eyes, it is easy to see that international relations cannot be observed or studied only from a highly scientific parsimonious point of view, because social facts are the result of social and historical developments, in which it is full of contingencies and inevitabilities, combined with different values [4].

\subsection{Applied Argumentation of Game Theory}

James Dougherty argues that for either the human brain or the world's largest computer, it is too difficult to comprehend the extreme complexity of international political games. In a tripartite game, in which each party can only takes limited and simple actions to response, or uses some mathematical method to analyze. But a triangular relation among America, the Soviet Union, and China during the Cold War, cannot be compared to a three-way game. Nor is it possible to imagine a pure triangle relation that would insulate Western Europe, Eastern Europe, Japan, and other important actors from the interaction of the three major powers [5].

Harrison Wagner points out that the assumptions of the Prisoner's Dilemma could not accurately model on international relations, in which one country usually responds based on the actions of another country or can learn about the other's intentions through a third party. And the repeated game of the Prisoner's Dilemma is not consistent with the real world, which is not fully repeatable. Therefore, even a repeatable game model does not provide a good overview of international affairs.

\section{CHINA'S INTERNATIONAL RELATIONS UNDER THE "PRISONER'S DILEMMA" OF THE ROLE OF GAME THEORY}

Taking into account the above arguments on how game theory plays its role, the value of game theory in the field of international relations should be affirmed. The following is an example of the classical game theory model applied to the decision-making of China's foreign policies, the whole process illustrates the usefulness of game theory for the study of China's international relations [6].

\subsection{Analysis of the Role of the "Prisoner's Dilemma"}

A political scientist at the University of Michigan (Robert Axelrod) proposed a strategy scenario in which he designed a two-person prisoner's dilemma game tournament. Game theorists from around the world submitted their strategies in the form of a computer program. Two people were paired in one group and played the Prisoner's Dilemma game 150 times over. All participants have their total score. The winner was Anatol Rapoport, a mathematics professor at the University of Toronto, whose winning strategy was a "tit for tat", which surprised Axelrod, who conducted another tournament, this time with more scholars. Rapoport continued to use his "tit for tat" strategy and won the highest scores again.

The idea of the competition is very simple: anyone who wants to participate in this computer competition plays the role of a prisoner in the Prisoner's Dilemma case, and they start playing the Prisoner's Dilemma game, each having to choose between cooperation and betrayal. The key issue is that they do not just play the game once, but hundreds of times over, in what is the so-called "repeated prisoner's dilemma," It is more realistically reflects the relational interaction between the two. This is another noteworthy condition; the simplest model of the prisoner's dilemma is a one-time game, and this is what exacerbates the prisoner's determination to come clean [7].

The results of the test surprised Axelrod, because the strategy adopted by the winner of the competition was not difficult at all: it was also called tit for tat. The Chinese call it "beat someone at their own game". In 
fact, the so-called tit for tat strategy is the principle of the carrot and stick approach. It insists on never betraying the other side in the first place, and believing everyone is well-intentioned. It will reciprocate its opponent's previous cooperation in the next round (even if this opponent had betrayed it before). In this sense it is forgiving. But it will take a betrayal action to punish the opponent for the previous betrayal, and in this sense it is tough. As the saying goes, "We will not attack unless we are attacked ". Therefore, the analysis shows that the country that has the following characteristics will always win: 1 . goodwill; 2 . tolerance; 3 . toughness; 4.having simple and clear intentions. Another explanation is that modern diplomacy differs from the traditional old-style diplomacy, which relied on the sophisticated and complex manipulations of politicians, so that in the game of modern diplomacy, clear intentions often bring the hoped-for results.

\subsection{The "Prisoner's Dilemma" in China's International Relations Game}

Just as classical realists argue that it is difficult to build trust between countries, due to it is a one-time game. As in the case of China and the United States relations, the game is generally repeated, and extensive cooperation on various international issues has been conducted after mutual exchange. And then their trust in each other will increase to varying degrees, because they have the opportunity to repeat the game, and there are countless opportunities to do "beat someone at their own game"[8].

In the relations between China and other countries, especially the United States, for example, according to Robert Axelrod's experiments, the victory also always goes to countries that are well-meaning, tolerant, tough, and simple and clear. Conversely, malicious, caustic, weak, and complex countries are doom to lose. Therefore, the principle of gaining diplomatic victory game should be:

First, treat other countries with kindness rather than malice. This truth is simple and obvious. Second, treating other countries with tolerance rather than harshness. Each country pursues its own national interests to the greatest extent possible, so the key to managing relations with other countries is to be able to tolerate each other, and even to tolerate their occasional, not very serious injuries. Countries that treat others harshly and refuse to accommodate occasional harm, like the United States, tend to make too many enemies, which will eventually lead to a much higher threat to domestic security, several times panic, and eventually suffer serious harm. For major countries who carry significant weight in the world economy, it is all the more necessary for them to take into full consideration the impact of their macroeconomic policies on others and increase the transparency of their policy-making process. Third, treating other countries toughly rather than softly should be done on the premise of being kind or beating someone at their own game. This, of course, requires people to do it appropriate manner. Sometimes it requires extremely strong sensitivity and quick feedback, for example, what China has done on the Taiwan problem makes people feel the Chinese government is just talking the talk, but never walking the talk. The problem in the past is that they talk too often but make little progress, all this make Taiwan and the US take those for a grant. The key to retaliation is that you must make the other side believe that you really want to take strong action and not just talk about it. Fourthly, the bottom line of your side in diplomatic issues should be clearly and simply stated. Axelrod's experiment proves that in the game process, overly complex strategies make it difficult for the opponent to understand and don't know what to do, thus making it difficult to establish a stable cooperative relationship. In fact, in the complex non-zero-sum game environment of international relations, "deep and rigid" and "not tired of deception" are definitely not the best strategy. On the contrary, a clear personality, concise style, and honesty hold the key to victory [9]. To let the other side understand what you are talking about, do not let the other side guess your intention, due to it is very easy to cause misunderstandings. The reason why there is a "China threat theory" is that, in the face of China's rise, the outside world does not see clearly what kind of role China will become in the future? What does China want? Because we have been adhering to Deng Xiaoping's principle of keeping a low profile and honoring our promises, with less empty talk in the international arena. However, the lack of simplicity and clarity eventually led to the misunderstanding of the outside world, which is why we later had to propose our own "peaceful rise" to regain the right to speak. The above example is a good illustration of the usefulness of game theory. We can see that game theory as a basic research tool is indeed beneficial for the study of international relations and foreign policy, and ensures its rationality [10].

\section{CONCLUSION}

In terms of China's international relations and foreign policy-making research, policy continuity, political culture, leaders' will, and ideological influence undoubtedly provide explanations form the view of the traditional research methods; however, from a scientific point of view, the possibility of strategic action provides another more intuitive and objective explanation. Game theory has been widely applied to the analysis of international politics and foreign policy decisions in the United States. But in China, given the different ideological characteristics and research processes in the study of international relations, the application of game theory to the analysis of international relations and foreign policy decisions is still relatively rare. For 
example, most of the existing studies on China's foreign policy decisions are empirical studies and post-verification analyses. Such analysis can be learned from historical lessons, but it is difficult to propose scientific countermeasures in the face of urgent real-world problems. Then, on the one hand, we should pay attention to the instrumental value of game theory, apply the theory with rigorous logical reasoning to foreign policy-making, and provide another way of thinking for foreign policy-making, so that China's foreign policy-making can be more scientific. On the other hand, trying not to fall into the deep terminology and complicated arithmetic of game theory, it is important to start from the basic principle of game theory, especially strategic thinking. It is worthwhile to combine the quantitative research method of behavioral science and the traditional qualitative research method of social science. This is how we can better promote the integration of game theory and Chinese international relations research.

\section{REFERENCES}

[1] Lindsay T. Hoyt, Katharine H. Zeiders, Natasha Chaku et al. Young adults' psychological and physiological reactions to the 2016 U.S. presidential election[J] Psychoneuroendocrinology, 2018, 92

[2] Artur Czumaj, Peter Davies Leader election in multi-hop radio networks[J] Theoretical Computer Science, 2019, 792
[3] Shay Kutten, Gopal Pandurangan, David Peleg et al. Sublinear bounds for randomized leader election[J] Theoretical Computer Science, 2015, 561

[4] Guy Louchard, Mark Daniel Ward The truncated geometric election algorithm: Duration of the election[J] Statistics and Probability Letters, 2015, 101

[5] Colin J Davis, Jeffrey S Bowers, Amina Memon Social influence in televised election debates: a potential distortion of democracy.[J] PLoS ONE, 2017, 6(3)

[6] INNS election results[J] Neural Networks, 1997, 10

[7] A. El Hibaoui, J.M. Robson, N. Saheb-Djahromi et al. Uniform election in trees and polyominoids[J] Discrete Applied Mathematics, 2010, 158(9)

[8] Presidentâs report on the election process[J], 1979, 1(4)

[9] AAD election under way[J], 1979, 1(4)

[10] Wanggi Jaung, L. Roman Carrasco, Jae Soo Bae Integration of ecosystem services as public values within election promises: evidence from the 2018 local elections in Korea[J] Ecosystem Services, 2019, 40 